\title{
Variability of plasma and urine betaine in diabetes mellitus and its relationship to methionine load test responses: an observational study
}

\author{
Michael Lever ${ }^{1,2^{*}}$, Sandy Slow ${ }^{1,2}$, David O McGregor ${ }^{3}$, Warwick J Dellow ${ }^{1}$, Peter M George ${ }^{1,2}$ and
} Stephen T Chambers ${ }^{2}$

\begin{abstract}
Background: Since betaine is an osmolyte and methyl donor, and abnormal betaine loss is common in diabetes mellitus (>20\% patients), we investigated the relationship between betaine and the post-methionine load rise in homocysteine, in diabetes and control subjects. The post-methionine load test is reported to be both an independent vascular risk factor and a measure of betaine sufficiency.

Methods: Patients with type 2 diabetes $(n=34)$ and control subjects $(n=17)$ were recruited. We measured baseline fasting plasma and 4-hour post-methionine load (L-methionine, $0.1 \mathrm{mg} / \mathrm{kg}$ body weight) concentrations of homocysteine, betaine, and the betaine metabolite $N, N$-dimethylglycine. Baseline urine excretions of betaine, dimethylglycine and glucose were measured on morning urine samples as the ratio to urine creatinine. Statistical determinants of the post-methionine load increase in homocysteine were identified in multiple linear regression models.
\end{abstract}

Results: Plasma betaine concentrations and urinary betaine excretions were significantly $(p<0.001)$ more variable in the subjects with diabetes compared with the controls. Dimethylglycine excretion $(p=0.00014)$ and plasma dimethylglycine concentrations ( $p=0.039$ ) were also more variable. In diabetes, plasma betaine was a significant negative determinant $(p<0.001)$ of the post-methionine load increase in homocysteine. However, it was not conclusive that this was different from the relationship in the controls. In the patients with diabetes, a strong relationship was found between urinary betaine excretion and urinary glucose excretion (but not with plasma glucose).

Conclusions: Both high and low plasma betaine concentrations, and high and low urinary betaine excretions, are more prevalent in diabetes. The availability of betaine affects the response in the methionine load test. The benefits of increasing betaine intake should be investigated.

Keywords: Betaine, Dimethylglycine, Methionine load, Homocysteine

\footnotetext{
* Correspondence: michael.lever@otago.ac.nz

${ }^{1}$ Biochemistry Unit, Canterbury Health Laboratories, PO Box 151Christchurch,

8140, New Zealand

${ }^{2}$ Department of Pathology, University of Otaga Christchurch, Christchurch,

New Zealand

Full list of author information is available at the end of the article
} 


\section{Background}

Betaine ("glycine betaine", "trimethylglycine" or "TMG") is a major osmolyte, accumulated in tissues for cellvolume regulation [1-3], and this tissue store is also a reservoir of methyl groups. Betaine is essential for life, and is obtained either from the diet $[4,5]$ or endogenously by the mitochondrial oxidation of choline [6]. Therefore it is of interest that more than $20 \%$ of patients with diabetes mellitus excrete abnormal amounts of betaine in their urine $[7,8]$, and it is worth considering the metabolic consequences of this loss. Betaine catabolism is mediated by betaine-homocysteine methyltransferase which is known to be regulated both by the supply of methyl groups [9] and by osmotic stress [10,11]. Through this enzyme, betaine is a major determinant of circulating homocysteine in mice [12], and in patients with lipid disorders the urinary excretion of betaine is the main factor affecting plasma homocysteine [13,14]. It has been suggested that betaine deficiency is a common feature of the metabolic syndrome $[15,16]$, and may be pathogenic. In a large cross-sectional study, low plasma betaine concentrations were associated with an unfavourable atherogenic risk profile. [17] and subjects with lipid disorders who excreted high levels of betaine appeared to have an increased incidence of vascular disease [18].

The methionine load test has been proposed as a measure of betaine sufficiency $[15,16,19]$, and the rise in homocysteine in this test is an independent risk factor for vascular disease [20,21]. We therefore compared the responses of patients with type 2 diabetes and matched control subjects in the methionine load test.

\section{Methods}

\section{Methionine load test study}

The study was approved by the Canterbury Ethics Committee (New Zealand) and all subjects gave written informed consent. Patients with Type 2 diabetes were identified through the Canterbury retinal screening programme database and invited to participate. Controls were recruited by posting notices around the hospital campus. Thirty four patients (aged 51-75 yrs, 20 males) and 17 controls (aged 54-69 yrs, 10 male) were recruited. They were asked to fast for 16 hours and to withhold morning medications. Their height, weight, age, and medical history were recorded. Venous blood was drawn into EDTA tubes that were placed on ice immediately for determining fasting plasma betaine and homocysteine concentrations and a urine sample was collected. They were then given a methionine load of $0.1 \mathrm{~g} / \mathrm{kg}$ body weight of L-methionine dissolved in $100 \mathrm{ml}$ fruit juice. They also ate a standard snack consisting of a jam (jelly) sandwich to avoid hypoglycaemia. They took no further food or fluid until their return 4 hours later, when a second venous blood sample was collected.
The betaine, dimethylglycine and homocysteine from the pre- and post- methionine load blood samples were measured in the same analytical batches.

\section{Analytical methods}

Betaine and N,N-dimethylglycine were measured in plasma and urine by high performance liquid chromatography (HPLC) as their 2-naphthacyl derivatives $[22,23]$. Plasma homocysteine was measured by fluorescence polarization on an Abbott $\mathrm{IM}_{\mathrm{X}}$ Analyzer (Abbott Laboratories). Creatinine was measured in plasma and urine using the Jaffé reaction on the fully automated Abbott Aeroset Analyzer (Abbott Laboratories, USA). Serum vitamin $\mathrm{B}_{12}$ and red blood cell (RBC) folate concentrations were measured by separate competitive immunoassays on an automated Chemiluminescence ACS:180 Analyzer (Chiron Diagnostics Corporation; USA). Hemoglobin $A_{1 c}$ was measured by the Diamat fully automated glycosylated hemoglobin analyzer system (Bio-Rad) and were expressed as a percentage of hemoglobin.

\section{Statistical methods}

Urine betaine and $N, N$-dimethylglycine excretions were positively skewed, and in the subjects with diabetes plasma betaine, dimethylglycine, homocysteine and serum vitamin $\mathrm{B}_{12}$ concentrations were also positively skewed. Where the raw data was not normally distributed (Kolmogorov-Smirnov test) the data were log transformed prior to conducting correlation and regression analyses. Associations were evaluated as Pearson's correlation coefficient and from multiple linear regression models. The regression models were based on the most significant variables that consistently appeared in at least 12 best subsets regression models (not reported), and only significant variables are included in the final models presented. Statistical analyses and figure preparation were carried out using SigmaPlot for Windows version 11.2 (Systat Software Inc).

\section{Results}

\section{Characteristics of the groups}

The subjects with diabetes were slightly older than the control subjects (Table 1). Almost all subjects were folate and vitamin $B_{12}$ replete. The fasting blood glucose concentrations of the subjects with diabetes were, as expected, higher than in the controls (Table 1), and the hemoglobin $A_{1 c}$ data shows that the subjects with diabetes had varied degrees of control.

\section{Differences between subjects with and without diabetes}

In this study, the medians of fasting plasma betaine and $\mathrm{N}, \mathrm{N}$-dimethylglycine concentrations, fasting plasma total homocysteine, the rise in homocysteine, and the 


\begin{tabular}{|c|c|c|c|}
\hline & $N$ & Median & Full range \\
\hline \multicolumn{4}{|l|}{ Females with diabetes: } \\
\hline Age (y) & 14 & 67.5 & $60-74$ \\
\hline Body Mass Index & 14 & 27.0 & $17.1-37.6$ \\
\hline Fasting plasma glucose $(\mu \mathrm{mol} / \mathrm{L})$ & 14 & 7.4 & $5.5-10.2$ \\
\hline Serum vitamin $B_{12}(p m o l / L)$ & 14 & 337 & $215-587$ \\
\hline Red cell folate (nmol/L) & 14 & 677 & $508-964$ \\
\hline Hemoglobin $A_{1 c}(\%)$ & 14 & 7.75 & $6.7-9.8$ \\
\hline \multicolumn{4}{|l|}{ Males with diabetes: } \\
\hline Age (y) & 20 & 69 & $51-75$ \\
\hline Body Mass Index & 20 & 27.2 & $22.1-42.3$ \\
\hline Fasting plasma glucose $(\mu \mathrm{mol} / \mathrm{L})$ & 20 & 7.85 & $4.8-14.8$ \\
\hline Serum vitamin $B_{12}(p m o l / L)$ & 20 & 330.5 & $129-697$ \\
\hline Red cell folate $(\mathrm{nmol} / \mathrm{L})$ & 20 & 655.5 & $406-1046$ \\
\hline Hemoglobin $A_{1 c}(\%)$ & 20 & 7.4 & $5.3-9.0$ \\
\hline \multicolumn{4}{|l|}{ Female control subjects: } \\
\hline Age (y) & 7 & 63 & $55-69$ \\
\hline Body Mass Index & 7 & 28.7 & $24.9-33.5$ \\
\hline Fasting plasma glucose $(\mu \mathrm{mol} / \mathrm{L})$ & 7 & 4.5 & $3.9-5.8$ \\
\hline Serum vitamin $B_{12}(p m o l / L)$ & 7 & 357 & $302-580$ \\
\hline Red cell folate (nmol/L) & 7 & 840 & $546-1071$ \\
\hline \multicolumn{4}{|l|}{ Male control subjects: } \\
\hline Age (y) & 10 & 57 & $54-66$ \\
\hline Body Mass Index & 10 & 26.8 & $21.1-36.5$ \\
\hline Fasting plasma glucose $(\mu \mathrm{mol} / \mathrm{L})$ & 10 & 4.75 & $3.9-5.8$ \\
\hline Serum vitamin $B_{12}(p m o l / L)$ & 10 & 355.5 & $227-837$ \\
\hline Red cell folate (nmol/L) & 10 & 847 & $507-971$ \\
\hline
\end{tabular}

excretions of betaine and $N, N$-dimethylglycine, were not significantly different between subjects with diabetes and controls (Figure 1). The striking difference is the greater variability of plasma betaine concentrations, and urine betaine excretions (Figure 1), in the subjects with diabetes. A similarly increased variability is apparent with $\mathrm{N}, \mathrm{N}$-dimethylglycine. The difference in variability was less pronounced for fasting plasma homocysteine and the rise in homocysteine after a methionine load (Figure 1), and a trend for higher variability in the subjects with diabetes was not significant in this study.

The post-methionine load plasma betaine and homocysteine concentrations were also significantly more variable in the subjects with diabetes (on logtransformed data, $p<0.001$ for betaine and $p=0.0016$ for $\mathrm{N}, \mathrm{N}$-dimethylglycine), as was the post-methionine change in plasma $N, N$-dimethylglycine $(p=0.013)$, but not the post-methionine change in plasma betaine $(p=0.7)$.

\section{Predictors of the post-methionine load increase in homocysteine}

In the subjects with diabetes, the statistically significant $(p<0.05)$ predictors of the post-methionine load increase in plasma homocysteine, identified by best subset regression, were fasting plasma homocysteine, either fasting or post-methionine load betaine, and (in most models) serum vitamin $\mathrm{B}_{12}$. Variables that did not enter any of 36 models with $p<0.1$ included age, body mass index, red blood cell folate, hemoglobin $\mathrm{A}_{1 \mathrm{c}}$, plasma glucose concentrations, plasma $\mathrm{N}, \mathrm{N}$-dimethylglycine concentration (either fasting or post-methionine load), and the urinary excretions of glucose, betaine and N,N-dimethylglycine. Log-transformed variables were used where the raw data was not normally distributed (Kolmogorov-Smirnov test). The three strongest candidate predictors (all log-transformed) were included in an explicit multiple linear regression model (Figure 2) which confirmed that the fasting plasma homocysteine was the strongest (positive) predictor, and the post-methionine load plasma betaine concentration was also a highly significant $(p<0.001)$ negative predictor. The serum vitamin $B_{12}$ concentration also a positive predictor $(p=0.021)$. The model explained most of the variance in the post-methionine load increase in homocysteine $\left(r^{2}=0.69\right)$. When the fasting plasma betaine concentration was included in the model instead of the post-methionine concentration, a similar result was obtained $\left(r^{2}=0.56\right)$ but the fasting betaine concentration appears to be a weaker negative predictor $(p=0.013)$.

The best subsets models of the post-methionine load increase in plasma homocysteine calculated on the control subjects either showed no significant predictors, or the fasting plasma homocysteine concentration appeared as a sole significant predictor. The same three-factor explicit multiple regression model was generated using the control data (Figure 2); this was a poorer model than when the subjects with diabetes were used $\left(r^{2}=0.32\right)$ and none of the terms were significant.

Regression models were also estimated using all subject data (combined controls and subjects with diabetes). In the three variable linear regression model $\left(r^{2}=0.58\right)$ both fasting homocysteine (positive) and post-methionine load plasma betaine (negative) were significant predictors $(p<0.001)$ but vitamin $\mathrm{B}_{12}$ was not significant $(\mathrm{p}=0.077)$. If diabetes ( 0 or 1$)$ was included as a variable in best-subsets regression models it was in no case significant. Age also did not enter any of the models as a predictor.

\section{Glucose, betaine and homocysteine}

Betaine excretion positively correlated with glucose excretion (log transformed data; $r=+0.47, p=0.005, n=34$ ) in patients with diabetes. Dimethylglycine excretion also correlated with glucose excretion (log transformed data; $r=+0.53, p=0.001, n=34$ ). There was an inconclusive 

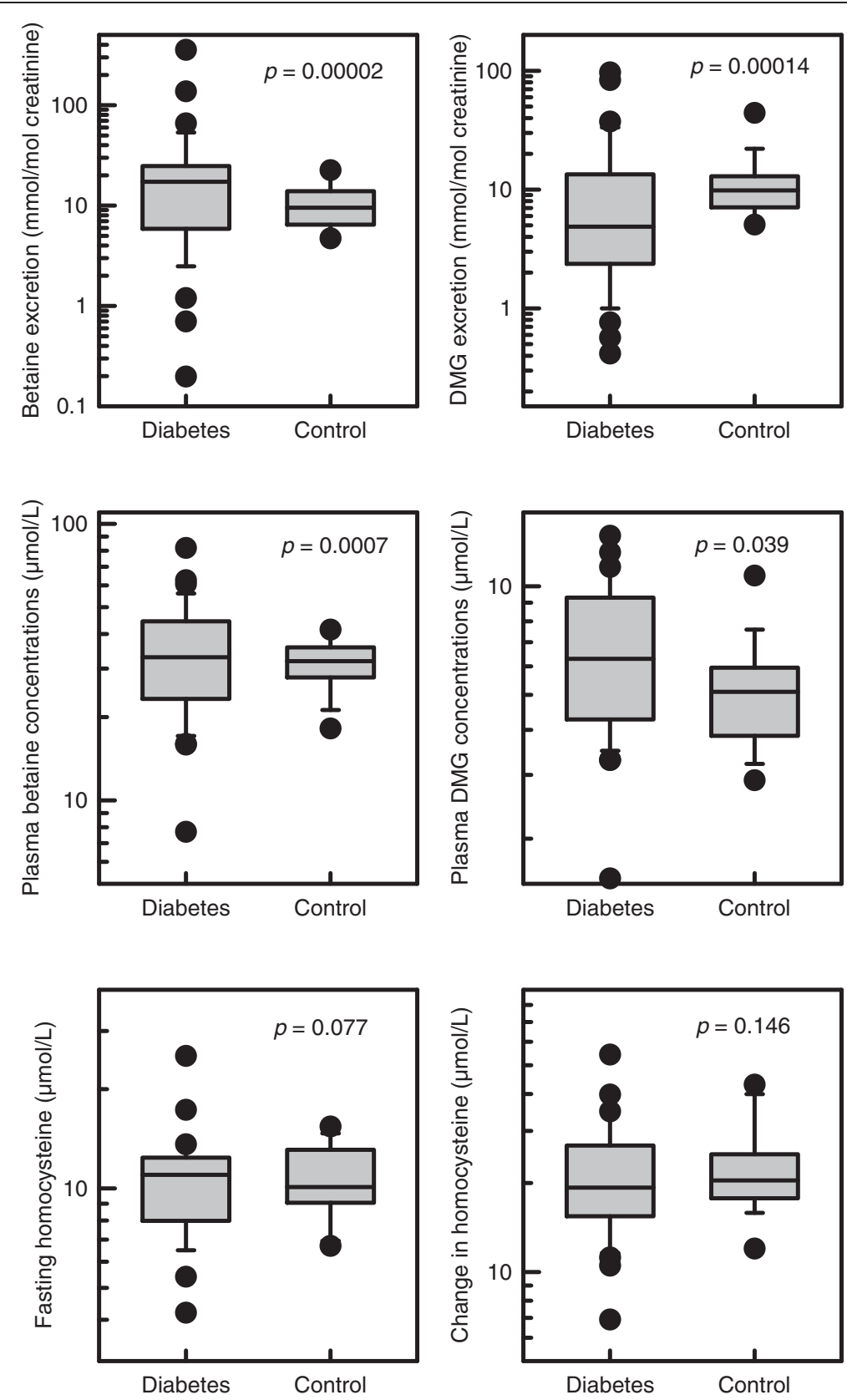

Figure 1 Variability of betaine and homocysteine metabolites. Variablity in subjects with diabetes $(n=34)$ and control subjects $(n=17)$. DMG: $N$, $\mathrm{N}$-dimethylglycine. The $p$ values are the significance of the differences between the variances of the subjects with and without diabetes, calculated using log-transformed data. The change in homocysteine is the difference between the plasma homocysteine before and $4 \mathrm{~h}$ after a methionine load; plasma betaine and homocysteine concentrations are fasting, before a methionine load.

correlation between plasma glucose and log-transformed betaine excretion $(r=+0.33, \quad p=0.056, \quad n=34)$; the Spearman's correlation coefficient was significant $\left(r_{s}=+0.37\right.$, $p=0.03)$. Neither fasting homocysteine, nor the post-methionine load increase in homocysteine, correlated with either plasma glucose or glucose excretion. Hemoglobin $\mathrm{A}_{1 \mathrm{c}}$ did not strongly correlate with betaine excretion, but there was a significant positive correlation $(r=+0.52, p=0.003$, $\mathrm{n}=30$ ) between hemoglobin $\mathrm{A}_{1 \mathrm{c}}$ and the post-methionine load change in plasma dimethylglycine (measured as the difference in $\log$ (plasma dimethylglycine) before and after the load). Hemoglobin $A_{1 c}$ did not correlate with either fasting homocysteine or the post-methionine load increase in homocysteine. 

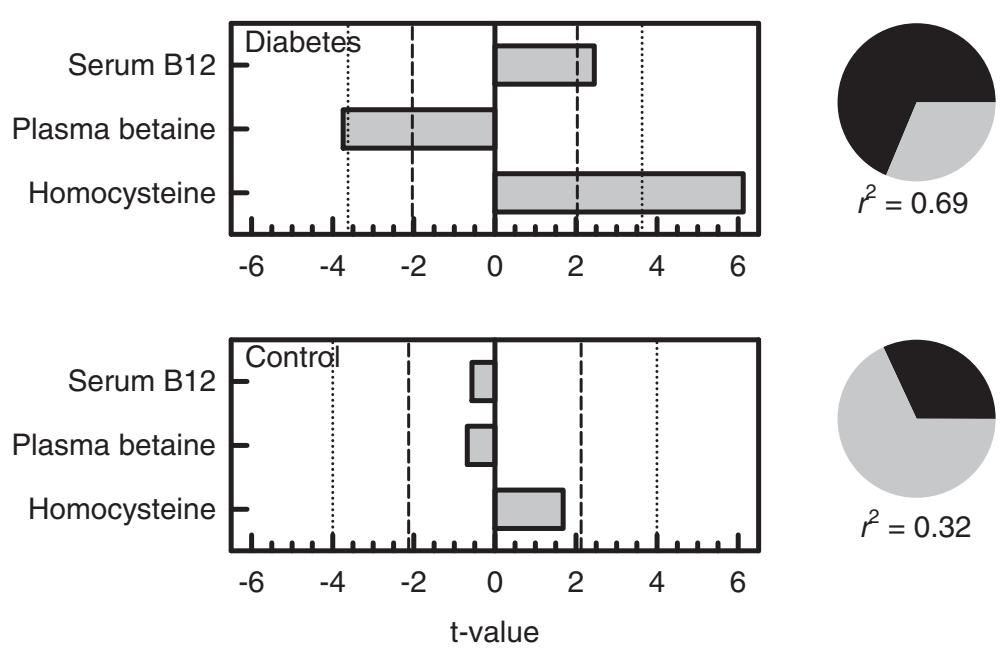

Figure 2 Multiple linear regression model for the post-methionine load increase in homocysteine. Top, in subjects with diabetes, bottom, control subjects. Dependent variable: log(rise in plasma homocysteine). Independent variables: log(serum vitamin $B_{12}$ ), log(post-methionine plasma betaine) and log(baseline fasting homocysteine). Bars show the significance of the factors as t-values, negative for a negative relationship and positive for a positive relationship; dashed lines $p=0.05$; dotted lines $p=0.001$. Pie graphs at the right show the proportion of variance (dark segment) explained by regression: unexplained variance in grey.

\section{Differences between subjects with high and low betaine excretions}

Data from all 51 subjects were combined and ranked on betaine excretion. The factors affecting the post-methionine load increase in homocysteine were identified in the highest and lowest tertiles of betaine excretion ( $n=17$ in each group) using best-subsets regression. In the highest betaine excretion group the three significant predictors of the increase in plasma homocysteine (expressed as log(rise in homocysteine)) were fasting homocysteine (log transformed), dimethylglycine excretion (log transformed) and age, and in an explicit three-variable multiple linear regression model (Figure 3) these explained $81 \%$ of the variance of the rise in homocysteine. Fasting homocysteine and dimethylglycine excretion were significant $(\mathrm{p}<0.001)$ positive predictors whereas age was a negative predictor. This three variable model was a poorer predictor in the middle and lower tertile groups of betaine excretion (Figure 3), explaining $<50 \%$ of the variance, and in the lower tertile there was a non-significant trend for dimethylglycine excretion to be negatively associated with the rise in homocysteine.

The differences between tertiles were also detected by Pearson correlation coefficients between the rise in homocysteine and fasting homocysteine (both log transformed) and with dimethylglycine excretion (also log transformed). In the upper tertile these were $r=+0.70(p=0.0018)$ and $+0.61(p=0.009)$ respectively; in the lower tertile they were $r=+0.61 \quad(p=0.010)$ and $-0.41 \quad(p=0.10)$. In the case of dimethylglycine excretion the two correlation coefficients were significantly different $(p=0.0024)$. This was further evaluated by comparing the highest and lowest quartiles of betaine excretion; in the highest quartile $(n=13)$ the corresponding correlation between the rise in homocysteine and dimethylglycine excretion was $r=+0.61 \quad(p=0.027)$ and in the lowest quartile it was $r=-0.62(p=0.024)$; despite the small numbers these are significantly different $(p=0.0013)$. In both quartiles the fasting homocysteine was a positive predictor of the post-methionine rise in homocysteine, $r=+0.86, p=0.00002$ in the highest quartile and $r=+0.65, p=0.017$ in the lowest quartile.

\section{Discussion}

Betaine is accumulated by most tissues as an osmolyte, with tissue concentrations much higher than plasma concentrations [3]. This tissue betaine is a major store of methyl groups. Mobilizing betaine involves methylating homocysteine to methionine, with the production of $N$, $N$-dimethylglycine [9], and betaine is probably the main regulator of non-fasting plasma homocysteine $[9,12,24]$. High urinary betaine loss is common in diabetes mellitus $[7,8,25]$, and may persist for years [26], potentially causing a betaine insufficiency that could be expected to have complex consequences, affecting both the ability of cells to maintain their volume and the supply of methyl groups essential for normal metabolism [15,16,27]. Other causes of deficiency could include a dietary insufficiency of choline plus betaine. Betaine is either obtained from the diet or by the mitochondrial oxidation of choline $[15,28]$, and defective conversion of choline to betaine is another possible cause. 

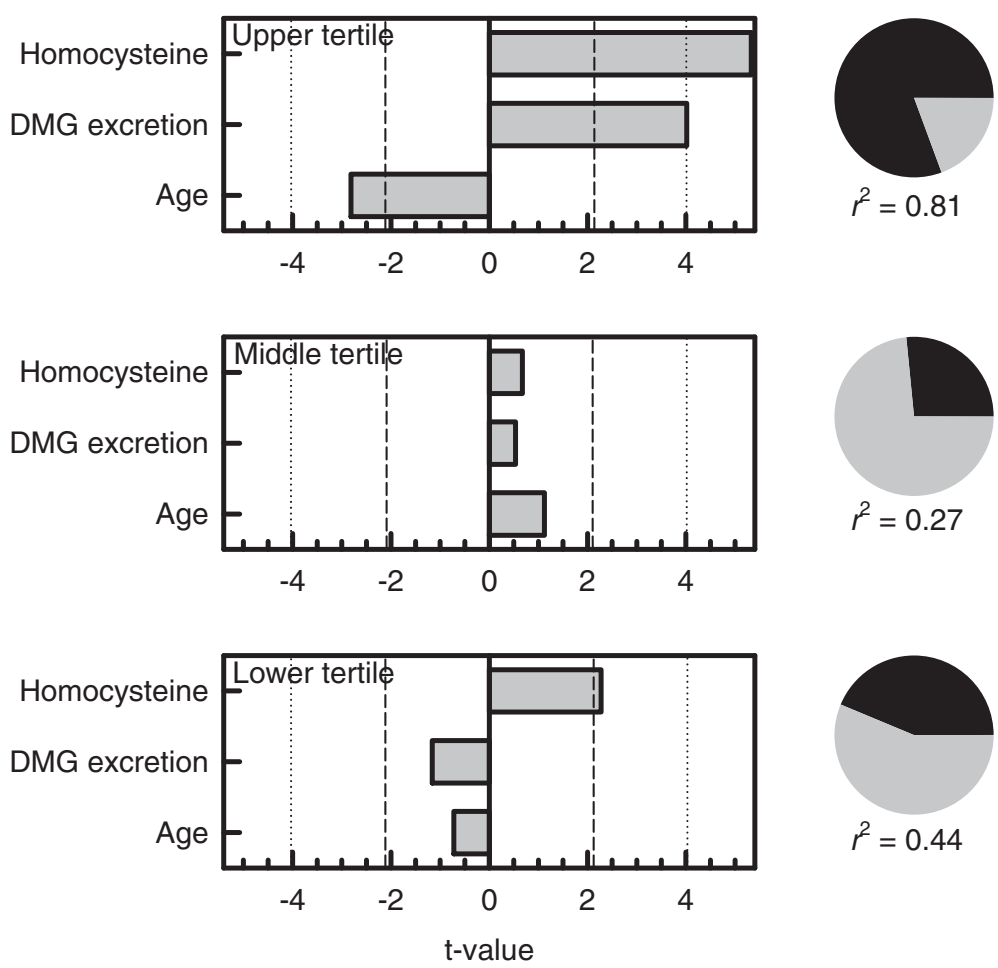

Figure 3 Multiple linear regression model for the post-methionine load increase in homocysteine. Data on subjects with diabetes and controls combined. Top, subjects in the highest tertile of betaine excretion and bottom in the lowest tertile of betaine excretion. Dependent variable: log(rise in plasma homocysteine). Independent variables: log(baseline fasting homocysteine), log(dimethylglycine excretion as mmol dimethylglycine per mole creatinine) and age (years). Bars show the significance of the factors as t-values, negative for a negative relationship and positive for a positive relationship; dashed lines $p=0.05$; dotted lines $p=0.001$. Pie graphs at the right show the proportion of variance (dark segment) explained by regression: unexplained variance in grey.

The most obvious difference between the subjects with diabetes and the control subjects is the greater variability in plasma and (especially) urine betaine in the patients with diabetes. This substantiates the impression presented visually in an earlier report [29], and could be explained by a higher prevalence of both elevated and decreased plasma and urine betaine in subjects with diabetes compared with the healthy population. Metabolites related to betaine, such as dimethylglycine and homocysteine, may also be more variable in diabetes, but a larger study would be needed to confirm this. Superficially, it appears that in the subjects with diabetes, plasma betaine is a stronger predictor of the postmethionine load rise in homocysteine than it is in the control subjects; however, this could be an artefact of the greater variance (in diabetes) of all the factors in the regression model. This possibility is supported by the failure of diabetes to appear as a significant factor when regression models are generated using the population of all subjects. Thus we confirm the findings of Holm et al. [19] about the importance of betaine in determining the post-methionine rise in homocysteine. Our finding that folate status failed to enter any of the regression models is also in agreement with Holm et al. [19]. Despite the possibility of bias being introduced by the age difference between subjects with diabetes and the control subjects, age was not a significant predictor of the post-methionine rise in homocysteine in any model, even those based on the combined population of all subjects.

This observational study cannot explain high and low plasma betaine concentrations in diabetes. Plasma betaine concentrations are normally tightly controlled $[15,25]$ and lower than intracellular concentrations [3]; efflux from cells is both osmoregulated and hormonally controlled. Compromise of this control could lead to elevated plasma concentrations. Low plasma concentrations may indicate a deficiency, for example as a result of urinary loss, defective synthesis from choline or poor dietary choices. High urinary excretion is presumably a renal phenomenon [15] and may be associated with the role of betaine as a renal osmolyte; low excretion is more likely to reflect a genuine deficiency. Methyl metabolism, including betaine metabolism, is disturbed in a rat model of diabetes [27] and suggests other mechanistic models 
to investigate: plausibly, the dual role of betaine could connect disturbed methyl metabolism with disturbed osmoregulation.

The post-methionine load increase in homocysteine has been proposed as a test for betaine insufficiency [1519]. This study supports this, though it was too small to answer the question of whether elevated post-methionine load responses were more common in diabetes, which would imply a greater prevalence of betaine insufficiency in diabetes. The subjects with diabetes and controls had similar ranges of BMI and there were fewer subjects with high betaine excretion in the diabetes group than we have found in other studies. Thus the negative result is inconclusive. However, the effect of betaine on this test was confirmed. The load test is commonly regarded as an independent risk factor for vascular disease [20,21] though its value has been questioned [30]. Betaine supplements have been shown to moderate the postmethionine load increase in homocysteine in normal subjects [19,31] and in renal failure patients [32]. The relationship between dimethylglycine excretion and the post-methionine load homocysteine response suggests hypotheses that could be tested. Dimethylglycine is the by-product of betaine-mediated homocysteine metabolism and an increased production of it implies an increased remethylation of homocysteine; the negative correlation between the two in some subjects with low betaine excretion suggests that this subgroup at least has a primary betaine insufficiency (insufficient betaine to moderate the rise in homocysteine), possibly because of an inadequate intake of choline plus betaine, or a defect in the mitochondrial oxidation of choline to betaine. The low correlations in the group of subjects around the median betaine excretion are likely to reflect the lower variances (in that group) of the variables.

This study does not address mechanisms for the elevated loss of betaine in many subjects with diabetes. However, betaine loss in at least some subjects with diabetes is associated with poor glucose control, and the correlation with urine glucose (rather than with plasma glucose) is consistent with this being a renal effect. It could be informative to investigate whether an increased production of sorbitol (another renal osmolyte) from glucose is a contributing mechanism, since sorbitol excretion is also elevated in diabetes and correlates with betaine excretion [7]. However, this model would need to be reconciled with the observation in a sheep model that elevated glucose itself does not directly cause an increased excretion of betaine [33].

Our results suggest that the supply of betaine may sometimes be limiting. Low plasma betaine has been associated with an unfavourable risk profile in observational studies $[14,32]$, but conversely (in another observational study) high plasma betaine has been associated with an increased risk of vascular events [34]. Since betaine, a major osmolyte, is well-known to be a protein-stabilizing compatible solute [35] and its intracellular concentrations are orders of magnitude higher than those in circulation [3] it is unlikely that an increase in circulating betaine can cause damage, though it may indicate a pathological process, as is seen in animal models when betaine-homocysteine methyltransferase is absent or inhibited $[24,36]$. Another possible pathological process is a failure of the tight control of betaine efflux from cells. Thus it is plausible that both high and low plasma betaine concentrations may reflect pathological processes. However, betaine supplementation can increase plasma betaine, lower plasma homocysteine, and is safe [37-39]. Betaine intake can be also be increased by dietary choices $[4,5]$. We suggest that urinary betaine excretion should be measured in patients with diabetes to identify those with excessive betaine loss. Such patients should be encouraged to increase their betaine intakes with high betaine foods such as whole wheat products $[40,41]$, spinach and beets $[4,5]$ or with betaine supplements.

\section{Conclusions}

In diabetes high and low plasma betaine concentrations are more common than in healthy subjects. Both high and low urinary betaine excretions are also more prevalent in diabetes, with the high excretions being associated with glucosuria. The availability of betaine affects the response in the methionine load test but it is not conclusively shown that this effect is more pronounced in diabetes. It would be interesting to investigate whether betaine supplementation of subjects with diabetes and abnormal betaine markers alters their risk of developing vascular disease.

\section{Competing interests}

There are no competing interests to declare.

\section{Authors' contributions}

ML, SS analyzed the data and took the main responsibility for preparing the MS. ML is responsible for the laboratory in which assays were carried out. DOM had the primary responsibility for the initial design, for recruiting subjects and supervising the methionine load test. WJD assisted DOM in recruitment and conducting the study, carried out the betaine assays in the laboratory and made an initial attempt at analyzing and interpreting the results.PMG had overall supervision and clinical input and input into interpreting the results and edited the MS during preparation. STC was partly responsible for the initial design and has overseen the work at all stages and edited the MS. All authors approve this submission.

\section{Acknowledgements}

Support from the National Heart Foundation of New Zealand, the Neurological Foundation of New Zealand, the Health Research Council of New Zealand, the Canterbury Medical Research Foundation and the Paykel Trust is acknowledged. None of these had any role in the conduct of the research or its interpretation.

\section{Author details}

'Biochemistry Unit, Canterbury Health Laboratories, PO Box 151Christchurch, 8140, New Zealand. ${ }^{2}$ Department of Pathology, University of Otaga Christchurch, Christchurch, New Zealand. ${ }^{3}$ Nephrology Department, Christchurch Hospital, Christchurch, New Zealand. 
Received: 28 February 2012 Accepted: 17 April 2012

Published: 17 April 2012

\section{References}

1. Burg MB, Ferraris JD, Dmitrieva Nl: Cellular response to hyperosmotic stresses. Physiol Rev 2007, 87:1441-1474.

2. Schliess F, Häussinger D: The cellular hydration state: a critical determinant for cell death and survival. Biol Chem 2002, 383:577-583.

3. Slow S, Lever M, Chambers ST, George PM: Plasma dependent and independent accumulation of betaine in male and female rat tissues. Physiol Res 2009, 58:403-410.

4. Zeisel SH, Mar MH, Howe JC, Holden JM: Concentrations of cholinecontaining compounds and betaine in common foods. J Nutr 2003, 133:1302-1307.

5. Slow S, Donaggio M, Cressey PJ, Lever M, George PM, Chambers ST: The betaine content of New Zealand foods and estimated intake in the New Zealand diet. J Food Composition Anal 2005, 18:473-485.

6. Zhang J, Blusztajn JK, Zeisel SH: Measurement of the formation of betaine aldehyde and betaine in rat liver mitochondria by a high pressure liquid chromatography-radioenzymatic assay. Biochim Biophys Acta 1992, 1117:333-339.

7. Lever M, Sizeland PCB, Bason LM, Hayman CM, Robson RA, Chambers ST: Abnormal glycine betaine content of the blood and urine of diabetic and renal patients. Clin Chim Acta 1994, 230:69-79.

8. Dellow WJ, Chambers ST, Lever M, Lunt H, Robson RA: Elevated glycine betaine excretion in diabetes mellitus patients is associated with proximal tube dysfunction and hyperglycaemia. Diab Res Clin Prac 1999, 43:91-99.

9. Park El, Garrow TA: Interaction between dietary methionine and methyl donor intake on rat liver betaine-homocysteine methyltransferase gene expression and organization of the human gene. J Biol Chem 1999, 274:7816-7824.

10. Delgado-Reyes CV, Garrow TA: High sodium chloride intake decreases betaine-homocysteine $S$-methyltransferase expression in guinea pig liver and kidney. Am J Physiol Regul Integr Comp Physiol 2005, 288:R182-R187.

11. Schäfer C, Hoffmann L, Heldt K, Lornejad-Schäfer MR, Brauers G, Gehrmann T, et al: Osmotic regulation of betaine homocysteine-Smethyltransferase expression in H4IIE rat hepatoma cells. Am J Physiol Gastrointest Liver Physiol 2007, 292:1089-1098.

12. Collinsova M, Strakova J, Jiracek J, Garrow TA: Inhibition of betainehomocysteine S-methyltransferase causes hyperhomocysteinemia in mice. J Nutr 2006, 136:1493-1497.

13. Lever M, Atkinson W, George PM, Chambers ST: Sex differences in the control of plasma concentrations and urinary excretion of glycine betaine in patients attending a lipid disorders clinic. Clin Biochem 2007, 40:1225-1231.

14. Lever M, Slow S, George PM, Chambers ST: Betaine excretion correlates with plasma homocysteine when plasma lipids are elevated. Clin Biochem 2012, 45:154-156.

15. Lever M, Slow S: The clinical significance of betaine, an osmolyte with a key role in methyl group metabolism. Clin Biochem 2010, 43:732-744.

16. Lever M, Slow S, Ueland PM: Betaine: osmolyte and methyl donor. In Vitamins in the prevention of human diseases. Edited by Herrmann W, Obeid R. Berlin: Walter de Gruyter; 2011:563-598.

17. Konstantinova SV, Tell GS, Vollset SE, Nygård O, Bleie Ø, Ueland PM: Divergent associations of plasma choline and betaine with components of metabolic syndrome in middle age and elderly men and women. $J$ Nutr 2008, 138:914-920.

18. Lever M, George PM, Dellow WJ, Scott RS, Chambers ST: Homocysteine, glycine betaine, and N, N-dimethylglycine in patients attending a lipid clinic. Metabolism 2005, 54:1-14.

19. Holm PI, Bleie O, Ueland PM, Lien EA, Refsum H, Nordrehaug JE, Nygard O: Betaine as a determinant of postmethionine load total plasma homocysteine before and after B-vitamin supplementation. Arterioscle Thromb Vasc Biol 2004, 24:301-307.

20. Bostom AG, Jacques PF, Nadeau MR, Williams RR, Ellison RC, Selhub J: Postmethionine load hyperhomocysteinemia in persons with normal fasting total plasma homocysteine: initial results from The NHLBI Family Heart Study. Atherosclerosis 1995, 116:147-151

21. van der Griend R, Haas FJLM, Duran M, Biesma DH, Meuwissen OJAT, Banga $\mathrm{J}$ : Methionine loading test is necessary for detection of hyperhomocysteinemia. J Lab Clin Med 1998, 132:67-72.
22. Storer MK, Lever M: Aracyl triflates for preparing fluorescent and UV absorbing derivatives of unreactive carboxylates, amines and other metabolites. Anal Chim Acta 2006, 558:319-325.

23. Storer MK, McEntyre CJ, Lever M: Separation of cationic aracyl derivatives of betaines and related compounds. J Chromatogr A 2006, 1104:263-271.

24. Strakova J, Williams KT, Gupta S, et al: Dietary intake of S-( $\delta$-carboxybutyl)DL-homocysteine induces hyperhomocysteinemia in rats. Nutr Res 2010, 30:492-500.

25. Lever M, Sizeland PC, Frampton CM, Chambers ST: Short and long-term variation of plasma glycine betaine concentrations in humans. Clin Biochem 2004, 37:184-190.

26. Lever M, Atkinson W, Chambers ST, George PM: An abnormal urinary excretion of glycine betaine may persist for years. Clin Biochem 2007, 40:798-801.

27. Williams KT, Schalinske KL: Tissue-specific alterations of methyl group metabolism with DNA hypermethylation in the Zucker (type 2) diabetic fatty rat. Diabetes Metab Res Rev 2012, 28:123-131.

28. Ueland PM: Choline and betaine in health and disease. J Inherit Metab Dis 2011, 34:3-15.

29. Lever M, Atkinson W, Sizeland PCB, Chambers ST, George PM: Inter- and intra-individual variations in normal urinary glycine betaine excretion. Clin Biochem 2007, 40:447-453.

30. Fokkema MR, Dijck-Brouwer DAJ, van Doormaal JJ, Reijngoud DJ, Muskiet FAJ: Low diagnostic value of fasting and post-methionine load homocysteine tests. A study in Dutch subjects with homocysteine test indications. Clin Chim Acta 2003, 331:153-157.

31. Atkinson W, Elmslie J, Lever M, Chambers ST, George PM: Dietary and supplementary betaine: acute effects on plasma betaine and homocysteine concentrations under standard and post methionine load conditions in healthy male subjects. Amer J Clin Nutr 2008, 87:577-585.

32. McGregor DO, Dellow WJ, Robson RA, Lever M, George PM, Chambers ST: Betaine supplementation decreases post-methionine hyperhomocysteinemia in chronic renal failure. Kidney Int 2002, 61:1040-1046.

33. Dellow WJ, Chambers ST, Barrell GK, Lever M, Robson RA: Glycine betaine excretion is not directly linked to plasma glucose concentrations in hyperglycaemia. Diab Res Clin Pract 2001, 52:165-169.

34. Wang Z, Klipfell E, Bennett BJ, Koeth R, Levison BS, DuGar B, et al: Gut flora metabolism of phosphatidylcholine promotes cardiovascular disease. Nature 2011, 472:57-63.

35. Timasheff SN: A physicochemical basis for the selection of osmolytes by nature. In Water and Life. Edited by Somero GN, Osmond CB, Bolis CL. Berlin: Springer-Verlag; 1992:70-84.

36. Teng Y-W, Mehedint MG, Garrow TA, Zeisel SH: Deletion of betainehomocysteine S-methyltransferase in mice perturbs choline and 1carbon metabolism, resulting in fatty liver and hepatocellular carcinomas. J Biol Chem 2011, 286:36258-36267.

37. Olthof MR, van Vliet T, Boelsma E, Verhoef P: Low dose betaine supplementation leads to immediate and long term lowering of plasma homocysteine in healthy men and women. J Nutr 2003, 133:4135-4138.

38. Schwab U, Torronen A, Meririnne E, Saarinen M, Alfthan G, Aro A, Uusitupa M: Orally administered betaine has an acute and dose-dependent effect on serum betaine and plasma homocysteine concentrations in healthy humans. J Nutr 2006, 136:34-38.

39. Schwab U, Alfthan G, Uusitupa M: Long-term effect of betaine on risk factors associated with the metabolic syndrome in healthy subjects. Eur $J$ Clin Nutr 2011, 65:70-76.

40. Price RK, Keaveney EM, Hamill LL, Wallace JMW, Ward M, Ueland PM, et al: Consumption of wheat Aleurone-rich foods increases fasting plasma betaine and modestly decreases fasting homocysteine and LDLcholesterol in adults. J Nutr 2010, 140:2153-2157.

41. Ross AB, Bruce SJ, Blondel-Lubrano A, Oguey-Araymon S, Beaumont M Bourgeois $A$, et al: A whole-grain cereal-rich diet increases plasma betaine, and tends to decrease total and LDL-cholesterol compared with a refined-grain diet in healthy subjects. Br J Nutr 2011, 105:1492-1502.

doi:10.1186/1475-2840-11-34

Cite this article as: Lever et al: Variability of plasma and urine betaine in diabetes mellitus and its relationship to methionine load test responses: an observational study. Cardiovascular Diabetology 2012 11:34. 